\title{
Effectiveness of message framing to improve oral health behaviors and dental plaque among pregnant women: a randomized field trial
}

\section{Masoumeh Divdar}

Ahvaz Jondishapour University of Medical Sciences Faculty of Public Health

Marzieh Araban ( $\square$ araban62@gmail.com )

Ahvaz Jondishapour University of Medical Sciences Faculty of Public Health https://orcid.org/0000-00019920-0261

\section{Akbar Babaei Heydarabadi}

Ahvaz Jondishapour University of Medical Sciences Faculty of Public Health

\section{Bahman Cheraghian}

Ahvaz Jondishapour University of Medical Sciences Faculty of Public Health

\section{Research article}

Keywords: Oral Health, Pregnancy, Message Framing, Dental Plaque

Posted Date: January 11th, 2021

DOI: https://doi.org/10.21203/rs.3.rs-16040/v2

License: (c) (i) This work is licensed under a Creative Commons Attribution 4.0 International License. Read Full License 


\section{Abstract}

Background: Oral health is considered as a prominent factor that contribute to quality of life. Hormonal changes during pregnancy can influence oral health. Message framing can play an important role in motivating oral health behaviors. The aim of the present study was to investigate the effect of message framing on the oral health behaviors and dental plaque among pregnant women.

Methods: This randomized field trial was conducted in 2017 on 108 pregnant women in Izeh county, Iran. The participants were randomly divided into three groups; gain-framed, loss-framed, and control group. The research instrument included a two parts questionnaire containing demographic information and oral health knowledge, attitude, behavioral intention, self-efficacy, practice, and dental plaque index. Gain-and lossframed messages were sent to the intervention groups via cell phones, but the control group did not receive any messages. The participants' dental plaque were clinically assessed. Data were analyzed using SPSS version, 23.0. P-value less than 0.05 was considered statistically significant.

Results: The mean scores of knowledge, attitude, behavioral intention, and self-efficacy were significantly increased in the gain- and loss-framed intervention groups (gain knowledge (6.05 $1.90 ; \mathrm{Cl}: 5.40-6.71)$; gain attitude(5.00 \pm 3.61 ; Cl:3.75-6.24); gain behavioral intention (2.91 \pm 1.59 ; $\mathrm{Cl}: 2.36-3.46)$; gain self-efficacy (4.42 \pm 2.69 ; Cl:3.50-5.35); loss knowledge (5.71 \pm 1.52 ; Cl:5.19-6.23); loss attitude (4.54 \pm 2.67 ; Cl:3.62-5.46); loss behavioral intention (2.25 $\pm 1.94 ; \mathrm{Cl}: 1.58-2.92)$; loss self-efficacy $(3.97 \pm 2.60 ; \mathrm{Cl}: 3.07-4.86)(\mathrm{p}<0.001)$. No significant difference was observed in the control group (knowledge $(0.38 \pm 1.45 ; \mathrm{Cl}: 0.12-0.89, \mathrm{p}=0.135)$; attitude (0.88 \pm 3.63 ; $\mathrm{Cl}: 0.38-2.14, \mathrm{p}=0.166)$; behavioral intention $(-0.38 \pm 1.74 ; \mathrm{Cl}:-0.98-0.22, \mathrm{p}=0.2)$; selfefficacy $(.0 .50 \pm 3.23 ; \mathrm{Cl}:-1.62-0.62, p=0.37)$. The rising trend in the mean score of the behaviors in the intervention groups was significantly higher than that in the control group $(p<0.001)$. The ratio of dental plaque on teeth surfaces in the gain- and loss-framed intervention groups also showed a significant decrease compared to control group (gain dental plaque (16.46 \pm 11.66 ; Cl:12.46-20.47, $\mathrm{p}<0.001)$; loss dental plaque (15.06 $\pm 8.52 ; \mathrm{Cl}: 12.13-17.99, \mathrm{p}<0.001)$.

Conclusion: Text message intervention improved knowledge, attitude, behavioral intention, self-efficacy, and dental plaque among pregnant women. The results show that text messages mattered, but the framing did not"; because there was a difference between intervention and control groups but not that "message framing matters" because the particular framing of the messages had no pronounced effect.

\section{Background}

According to World Health Organization (WHO), oral health is a prominent indicator of overall health, wellbeing and quality of life [1]. Moreover, oral health is considered as an important factor that determine different aspects of quality of life (physical, mental, and socioeconomic) [1,2]. With regard to increased communications as well as various social situations among people in today's society, the inevitability of adherence to oral health is felt much more than ever before [3]. The burden of oral diseases has also grown by $20 \%$ from 1990 to 2010 globally [4]. In this resepct, the results of nation-wide studies have similarly indicated that oral health in Iran's society is at a moderate level, according to the WHO report in 2000 [2]. Many adults around the world are also at the risk of dental caries and periodontal diseases $[5,6]$, caused by 
the activity of bacteria in dental plaque [7]. To improve oral health status in adults, prevention programs need to be performed before birth [8]. Physiological changes in the mouth occurring during pregnancy have been similarly confirmed [9]. It should be noted that pregnancy is a very important event in a woman's life which has high potential to affect her and her child's health status [10]. Hormonal changes and nutritional conditions can also make pregnant women susceptible to gum diseases and dental caries $[1,11,12]$. Early morning nausea and vomiting, too much consumption of sugar and other foodstuff, as well as less use of toothbrush and floss can ultimately lead to the formation of microbial plaque and dental caries [13].

Periodontal diseases are also associated with antenatal complications and childbirth such as early birth, low birth weight, limited intrauterine growth, or small embryos for its gestational age $[11,12,14,15]$. It should be further noted that pregnant women can suffer from dental caries by 2.9 times than non-pregnant ones [16]. Despite the fact that the risk of oral diseases during pregnancy is high, pregnant women use less dental care and ignore oral hygiene than the general population. Based on surveys conducted around the world, it has been estimated that $58-65 \%$ of pregnant women are not committed to oral care $[1,17,18]$. In this regard, the results of the study by Bayat et al. on pregnant women in the city of Hamadan, Iran, showed that $68 \%$ of such individuals were brushing their teeth once a day, and only $11.8 \%$ of them were doing so after each mealtime [13]. In an investigaiton by Moawed et al., pregnant women reported several common factors hindering their access to oral care including lack of information about oral health, insufficient time, and fear of dental treatments; indicating that these individuals were in need of much more information on oral care [19]. Therefore, oral health education can be taken into account as one of the most important and critical factors in preventing plaque formation as well as occurrence of dental diseases [20]. However, the effectiveness of a health education program depends largely on the use of an appropriate educational theory [21]. Kahneman and Tversky in 1979 proposed that health messages can be framed in terms of either the benefits of engaging in the recommended behaviour (gain-framed messages) or the costs of not engaging in the behaviour (loss-framed messages). Although conveying essentially identical information, one form of message framing may be more effective at promoting health behaviour change than the other. Specifically, loss-framed messages might be persuasive for illness detection behaviours, such as mammography or skin cancer detection, while the gain-framed messages should be more persuasive for illness prevention behaviours, such as physical activity promotion[22].

Gain and loss framed messages are largely inconsistent in their level of persuasiveness. However, earlier meta-analysis showed no statistically significant difference in the persuasiveness of gain- and loss-framed appeals for certain domains[23]. Updegraff et al., 2015 showed that participants who watched a video where the frame (gain/loss) matched perceived susceptibility (low/high) had significantly greater likelihood of flossing[24]. Ramezankhani et al., 2016 showed that the attitude, intention and behavior of using dental floss and tooth brush in students who received gain-framed message compared to those who received lossframed message increased [25].

The findings of a study conducted in the United States also revealed that a large percentage of adults (92\%) owned a cell phnoe allowing the distribution of information through text messages and it could be also used to send messages related to health threats [26]. Therefore, the issue of effectiveness of health-realted message framing on individuals in society regarding more favorable attitudes makes the intention to adopt such health-realted behaviors a necessity and it is of utmost importance to examine such differences [25]. 
Following decades of research in message framing, a systematic review suggest that message framing may have effect on health behavior,the study proposed the likelihood of a framing effect under specific conditions [27].

Accordingly, the objective of this study was to investigate the effectiveness of message framing on oral health-related behaviors and also its impact on dental plaque index among pregnant women. The study had two hypothesis. The first is that message framing intervention could promote oral health behavior and index and the second is that gain-frame group would be better than control group.

\section{Methods}

\section{Participants}

The present randomized field trial was carried out in Izeh (southwest of Iran) From November 2017 to February 2018. A total of 104 participants pregnant women reffered to Physiologic Birth and Counseling Center for antenatal training classes were selected for the study. The participants were randomly assigned to intervention (receive either gain- or loss-framed text messages) and control (did not receive any messages) groups .

\section{Inclusion criteria}

The inclusion criteria in this study were being able to read and write, access to cell phones, willingness to participate in the study, not having high risk pregnancy as diagnosed by their midviwes, not having an underlying disease (cardiovascular disease, autoimmune disease, cancer, diabetes, etc.), gestational age of 16 to 28 weeks, as well as age ranges between 18 and 35 years. The women were selected using nonprobabilty convenience sampling method.

\section{Intervention}

Two cell phone numbers were taken from pregnant women for the delivey of messages and follow- up. Since "prospect theory" is a much more wide field than Goal framing, the study is focused much on "Goal framing[27] for designing the messages. The desired intervention was composed of 30 identical messages in terms of concept, but different considering the frame which was associated with advantages and disadvantages of not using toothbrushes, dental flosses, and mouthwashes; developed by examining and referring to texts and using message design principles[28]. Then, the given intervention was sent in the form of SMS as a message per day to the individuals in gain- and loss-framed intervention groups, but the control group did not receive any messages. For example, the gain-framed intervention group recieved the message of "If you floss every day, you will have a beautiful smile" while the following message was sent to the lossframed intervention group; "If you do not floss every day, you may be embarrassed with your smile" [29]. Validity and reliability of messages was confirmed using validity checklist of messages[30], The pregnant women were also asked to ensure researchers of receiving the messages through replying by a blank message sent to them. If the researcher did not receive a message from pregnant women after 3 days [31], they would call them or sent them educational messgaes through other cell phone numbers. Eight weeks after sending the messages, the post-test questionnaire was completed by the three study groups in person. 


\section{Outcomes Measures}

\section{Demographic data sheet}

The first part of the questionnaire included demographic characteristics as well as previous pregnancy history which was comprised of 14 items (maternal age, husband's age, duration of marriage, gestational age, maternal occupation, husband's occupation, coverage of healthcare insurance services, maternal level of education, husband's level of education, previous pregnancy history, maternal ethnicity, monthly houshold income, family size, and place of residence).

\section{Questionnaire}

The second part of the questionnaire consisted of the constructs of knowledge about general health and oral health and hygiene during pregnancy, attitude, behavioral intention, self-efficacy, and practice in mothers concerning oral health. The construct of knowledge with 14 items had been developed about the prevention of oral problems (additional file 1) and was scored as follows; a correct answer was rated 1 and an incorrect answer was assigned with 0 . The construct of attitude consisted of 10 items, the behavioral intention contains 6 items, and self-efficacy was comprised of 9 items that had been desigend based on a 5-point Likert-type scale. In terms of scoring, positive items were rated 1, 2, 3, 4, and 5 for totally disagree, disagree, neutral, agree, and totally agree; respectively. This scoring was also done in reverse for negative items which had been used in the construct of attitude. The final part of the questionnaire contained 14 items relating to women's practice in terms of oral care which were given a score of 1 based on correct and incorrect answers. Items about how to brush and floss the teeth were further completed through direct observation of preganat women's performace on a mouth and teeth model (examining cases such as correct movement angle or angular $45^{\circ}$ of the toothbrush for different parts of the tooth, use of vibrating movements on gum lines, horizontal movement in the occlusal surface, vertical movement of the brush on the anterior and internal surface of the tooth, break-off of suitable floss size, correct winding of the floss around fingers, correct movement of the floss between the teeth and gum line, etc.). Other functions performed by such pregnant women were also recorded in the from of self-reprots.

\section{Validity and reliability}

In order to determine the scientific validity of the method, content validity and face validity were employed. Therefore, the opinions of 10 professors in this field were elicited. After summarizing expert opinions, content validity ratio and content validity index were calculated. Using the cut-off point in Lawshe's table, comparisons showed that the obtained number was greater than that specified in the table (0.99) [32]. After summarizing expert opinions, content validity ratio and content validity index were calculated. The content validity index was found to be perfect $(\mathrm{CVI}=1)$. To measure its face validity, the questionnaire was submitted to 10 pregnant women with conditions similar to those of the target group to have their impression of the importance of the questionnaire items via a 5-point Likert-type scale including absolutely important, important, moderately important, slightly improtant, and absolutely not important. The face validity of the questionnire was approved (impact score 4.5). 
The reliability of the questionnaire was also confirmed. The scientific reliability of this research instrument was determined by the researcher using test-retest method. To this end; in a pilot study, the questionnare was given to 10 pregnant women meeting the inclusion criteria within a 14-day interval and it was recompleted by them after two weeks. The Pearson correlation coefficients for the constructs of attitude, behavioral intention, self-efficacy, and practice were by $0.89,0.89,0.91,1$; respectively. For the knowledge alpha Cronbach's was used to assess internal consistency, the result found to be satisfactory, 0.80 .

\section{Oral health examinations}

The examination of the pregnant women's teeth was also fulfilled by a dentist and according to the required standards and then the percentage of dental plaque was measured using a dental plaque index (i.e: NPI) [17, 33]. The given index was a valid tool which had been utilized by different researchers. The measurements were performed using disclosing tablets along with plaque measurement chart. In order to calculate the accuracy of the measurment through the dental plaque index by the dentist, the dental plaque was measured shortly after the main measurement for 10 participants in the study. Internal consistency was also performed and approved using Cronbach's alpha coefficient (0.9).

\section{Sample size}

To determine the sample, the formula for comparing the means was used in which $\alpha=0.01$ and $\beta=0.1$ and $x 1=0.07$ (Gain frame Flossing means changes in baseline and week 24) , x2 $=0.09$ (Control Flossing means changes in baseline and week 24), s1=0.147(of the week 24), s2=0.123(of the week 24), based on the results of similar previous studies* [6].

$$
n=\frac{\left(s_{1}^{2}+s_{2}^{2}\right)^{2}\left(z_{1-\frac{\alpha}{2}}+z_{1-\beta}\right)^{2}}{\left(\bar{x}_{1}-\overline{\boldsymbol{x}}_{2}\right)^{2}}
$$

The sample size was considered to be three groups of 36 , and a total number of 108 individuals were estimated.

\section{Randomization}

Participants divided into three groups; gain-framed intervention group, loss-framed intervention group, and control group using block randomization technique via 6 blocks. The block size was 6 . Block randomization applied in this study is a commonly used technique in clinical trial design to reduce bias and achieve balance in the allocation of participants to intervention/treatment arms, especially when the sample size is small. This method increases the probability that each arm will contain an equal number of individuals by sequencing participant assignments by block. This approach was done with WinPepi11.0 software. This software generates random groups. In each block, 3 subjects were from the control group and 2 subjects were assigned to gain-group, 2 snumbers to loss-fram and 2 numbers to the control group, which all numbers were arranged randomly. Finally, 16 blocks were used. The steps of using the software listed were as follows: Aetcetera, Randomization (Random allocation)Balanced Randomization, Successive blocks.

\section{Blinding}


The validity of the messages was approved through a message validity checklist. In order to ensure no information bias, the study design was selected as a double-blind type in such a way that the participants were kept unaware of the type of the received messages (gain- and loss-framed ones), and also the assessor of the dental plaque (the dentist) was kept uninformed of the allocation of the given individuals into the groups. Two reseach assistants helped with random allocation, and assigned participants to study gropus.

\section{Data analysis}

Results were analyzed in SPSS 23.0 using dependent t-test and Chi-square analysis. The Kolmogorov Smirnov test was employed to determine the normality of data distribution. Analysis of variance (ANOVA) or its non-parametric equivalent was also utilized to compare quantitative values between the three groups. The relationship between qualitative variables was similarly measured through test. To compare attitude, behavioral intention, self-efficacy, and practice of the two intervention groups, the analysis of variance (ANOVA) was used considering the initial values. The significance level was considered at 0.05. G power was used to estimate the power of the study.

\section{Ethics}

All participants were informed about the study and confidentiality protocols. Informed consent was obtained from participants. The Ethics Committee of Ahvaz Jundishapur University of Medical Sciences confirmed the morality and ethics of that study (IR.REFERENCE.REC.1396.554).

\section{Results}

The mean age of the participants in this study was $27.4 \pm 4.37$ years with a minimum age of 18 and a maximum age of 35. The homogeneity of the groups in terms the demographic characteristics affecting the study results including maternal age, gestational age, maternal occupation, maternal level of education, previous pregnancy history, maternal ethnicity, monthly household income, place of residence, and coverage of healthcare insurance were illustrated in Tables 1 and 2.

The mean and standard deviation of the variables were similar at the beginning of the study and no significant difference was observed in all groups. Moreover, the normality of the groups was measured using Kolmogrov-Smirnov test and, if necessary, ANOVA and Chi-square test with a significant level of $p<0.05$ were used. The mean score of the constructs of knowledge, attitude, behavioral intention, self-efficacy, and practice in the intervention and control groups were presented in Table 3.

In this study, the mean difference of knowledge before and after intervention in the gain-framed intervention group, loss-framed intervention group, and control group were reproted by $6.28,5.72$, and 0.38 ; respectively. There was also a statistically significant difference in the mean score of knowledge in the intervention groups compared with that of the control group $(p<0.001)$. The mean score of knowledge in the intervention groups was not statistically significant $(0.34 \pm 0.39 ; \mathrm{Cl} ;-0.59-1.27, \mathrm{P}=0.65)$

Based on the results of ANOVA, the mean score of attitude in preganant women regarding oral- dental care before the educational intervention in the intervention and control groups did not show a significant 
difference. However, following intervention, the mean scores of attitude in individuals in the gain- and lossframed intervention groups were respectively by 44.40 and 42.44 , which were significantly higher than that of the mean score attitude in individuals in the control group (38.82) $(4.11, \mathrm{Cl} ; 2.20-6.02,3.66, \mathrm{Cl} ; 1.75-5.56$, $\mathrm{p}<0.001)$. This increase in intervention groups was not statistically significant $(0.45, \mathrm{Cl} ;-1.43-2.35, \mathrm{p}=0.83)$.

Furthermore, the findings of this study showed that the mean score of behavioral intention (gain: $27.28 \pm 2.05$, loss: $26.77 \pm 2.34$ ) and self-efficacy (gain: $38.91 \pm 3.23$, loss: $38.34 \pm 3.42$ ) in the intervention groups had significantly augmented after the intervention compared with that of the control group (behavioral intention: 23.67 \pm 2.71 , self-efficacy: $33.79 \pm 5.15$ ) (gain behavioral intention: $3.29, \mathrm{Cl} ; 2.28-4.30$,loss behavioral intention:2.63, 1.62-3.65, p<0.001)(gain self-efficacy:4.92,Cl; 3.29-6.56, loss self-efficacy:4.47,Cl; 2.83-6.10, $\mathrm{p}<0.001$ ) , but there was no significant difference between the two intervention groups (behavioral intention:0.65, $\mathrm{Cl} ;-0.34-1.66, \mathrm{p}=0.27$ ) (self-efficacy:0.45, $\mathrm{Cl} ;-1.16-2.07, \mathrm{p}=0.78$ ). The results also revealed that the maximum decrease in dental plaque index was related to pregnant women in the gain-framed intervention group (16.46 \pm 11.66$)$; however, no significant difference was observed with the loss-framed (1.40, Cl; -3.56$6.36 p=0.78)$. On the other hand, there was a significant difference between the mean scores of dental plaque in the intervention groups (gain: $19.71 \pm 9.71$, loss: $23.62 \pm 10.72)$ and the control group $(36.87 \pm 11.74)$ $(p<0.001)$. Based on the results of ANOVA, the amounts of decline in the dental plaque index in individuals in the gain-framed intervention group, the loss-framed intervention group, and the control group were by $16.47 \%$, $15.07 \%$, and $2.16 \%$; respectively.

In this study, the mean score of maternal practice concerning oral care before the educational intervention in both gain and loss-framed intervention groups implied no significant difference. However, a significant increase was observed in the mean scores of the gain(11.00 \pm 1.10$)$ and loss $(10.25 \pm 1.48)$ framed groups after intervention compared with that of the control group $(7.55 \pm 2.21)(3.35, \mathrm{Cl} ; 2.26-4.44,3.12, \mathrm{Cl} ; 2.03-4.21, \mathrm{p}<0.001)$ while no satistically significant difference was reported between the intervention groups $(0.22, \mathrm{Cl} ;-0.85-1.31$, $\mathrm{P}=0.87$ ). It should be noted that the statistical significant increase over the study period in control group may not necessarily be clinically significant.

The power analysis of the study was obtained as 0.93 .

\section{Discussion}

The purpose of the present study was to invetigate the effect of an education program based on message framing on oral health-related behaviors among pregnant women in the city of Izeh, Iran. To control the intervening variables, to ensure that the study groups were homogeneous in terms of demographic characteristics, and also to verify the accuracy of the findings in this study. Empirical studies have demonstrated that message frame can improve people decisions. As well as, gain-framed messages can be more persuasive for health prevention behaviour and loss-framed messages can be more persuasive for health detection behaviour [34-36]. However, this study showed that framed messages would strengthen the mean score of knowledge in both intervention groups compared with that of the control group. Although, no significant difference was observed between gain-framed and loss-framed messages. In this regard, the findings of the study by Ghajari et al. showed that education based on message framing could improve students' knowledge in both gain- and loss-framed intervention groups compared with the control group [29, 
37]. The results of the study by Fatahi et al. in the city of Yazd, Iran, in 2001, also demonstrated that sending educational messages via cell phones could significantly enhance knowledge in diabetic patients.

Besides, the findings of the present study showed that the mean score of attitude in both intervention groups had increased compared with that of the control group. However, there was no statistically significant difference between the gain- and loss-framed intervention groups. The results of the study by Pakpour et al. suggested that students who had received loss-framed messages were endowed with stronger tendency towards using toothbrush and floss compared with those who had received gain-frmaed messages [38, 39]. This difference might be due to the discrepancy in the target groups. On the other hand, in the study by Pakpour et al., the impact of cultural conditions on the outcomes were highlighted, which could be regarded as an important component. Moreover, the results of the study by Uskul et al. revealed that British white participants who had stronger intentions had been conviced by gain-framed messgaes, while participants in East Asia, who were endowed with preventive intentions, had been encouraged by loss-framed messages [38, 40].

Considering the mean score of self-efficacy, a significant increase was observed in both loss- and gainframed intervention groups compared with the control one. However, no statistically significant difference was reported in the intervention groups and both intervention groups were equally effective.

The results of the study by Merdasi et al. indicated that message framing could enhance self-efficacy of breastfeeding in nulliparous women in gain- and loss-framed intervention groups, although no statistically significant difference was reported between these intervention groups [30]. While the mean score of practice in gain- and loss-frmaed groups showed a significant increase compared with that of the control group, there was no statistically significant difference between both intervention groups.

It should be noted that oral health-related behaviors such as brushing the teeth and flossing them have been recognized as two-state behaviors (i.e. behaviors targeting early diagnosis or behaviors targeting dental caries) [38]. Moreover, individuals' motives could play a role in regulating numerous behaviors, so considring such motives could be effective in determining how oral health-related messages to various people could be designed. Based on the Theory of Motivation, individuals who were approach-oriented could change their behaviors through a gain-framed oral health message and those who were avoidance-oreinted could adhere to loss-framed ones [41]. Therefore, various outcomes are expected in different studies adopting preventive or diagnostic approaches and also employing target groups with diverse motivational approaches.

The study by Gallagher et al. revealed that gain-framed messages had much more capacity than loss-framed ones to encourage preventive health-related behaviors particularly to prevent skin cancer, to quit smoking, and to perform physcial activities [34] which was consistent with the results of the present study, although they were not significant. Furthermore, Schneider et al. reiterated that loss-framed messages had more impacts on accpetance and completion of mammography [42].

Distance learning can be effective because of the elimination of spatial and temporal constraints, and consequently establishment of an effective relationship with patients [30,43]. In this resepct, the study by Gharaati et al. emphasized these results. The findings of this study also demonstrated a significant increase 
in the mean scores of knowledge, attitude, and self-care behaviors in the intervention group following the fulfillment of the intervention, but no significant difference was observed in the control group [43]. The results of the study by Haghani et al. similarly indicated the effectiveness of message-based education method in providing antenatal education [44]. Naderi et al. also concluded that use of cell phones could have a significant impact on students' metacognitive self-regulation as well as their attitudes towards cell phoneassisted learning [45].

Analysis of dental plaque scores showed no significant difference between gain-framed and loss-framed messages. Moreover, there was a significant difference between the intervention groups compared with the control group. Additionally, the reduction of dental plaque in this study confirmed the improvement of pregnant women's practice.

As well, Lafzi et al. reproted that a significant decrease had occurred in the dental plaque index from $72 \%$ to $38 \%$ in the intervention group following two-month education which was in line with the findings of the present study. In the study by Shamsi et al., the mean difference of dental plaque index in the intervention and the control groups were significantly different. This rising trend in pregnant women's practice consequently led to improved oral health and better dental plaque indices in individuals in the intervention group [17]. Considering no statitistically significant difference between two types of framed messages in the educational intervention, other reasons except the same effectiveness of these two types of frames could be highlighted. So; the messages could be more effective if their presentation was sequantial and consequently the finidings would be different. On the other hand, the inappropriate time of intervention could be taken into account as one of the factors shaping the effectiveness of the delivered messages. Moreover, the non-significance of the expected results could be because of no deep, accurate, and effective attention to health-related messages.

In most cases, there was much more increase in the outcomes of the study including the mean score of knowledge, behavioral intention, and self-efficiacy associated with oral health after sending messages to the gain-framed group compared with that of loss-framed and control goups. Furthermore, the percentage of dental plaque in the gain-framed group) 16.47) was more than that of loss-framed (15.06) and control groups $(2.16 \%)$ although the results were not statistically significant. These findings were in agreement with the results of related investigations [25]. Thus, it was concluded that development of theory-based oral health programs could be effective and also efficiant in terms of providing education to pregnant women in this domain.

The power analysis of the study was obtained as 0.903 showing that the power is large enough to make decision about the effectiveness of the intervention.

\section{Limitations}

The findings could not be generalized to the entire community of pregnant women, given the further visits by such individuals residing in urban areas compared with those with limited visits in rural ones due to long distance and other problems. The volunteering of participants in the research may indicate their motivation, which acts as an intermediary variable not controlled in this study. 


\section{Conclusion}

Text message intervention improved knowledge, attitude, behavioral intention, self-efficacy, and dental plaque among pregnant women. The results show that text messages mattered, but the framing did not"; because there was a difference between intervention and control groups but not that "message framing matters" because the particular framing of the messages had no pronounced effect.

\section{List Of Abbreviations}

Navy Plaque Index (NPI), short message system (SMS)

\section{Declarations}

\section{Ethics approval and consent to participate}

All participants were informed about the study and confidentiality protocols. Informed consent was obtained from participants; this study was obtained from an earlier research (SDH-9614). The Ethics Committee of Ahvaz Jundishapur University of Medical Sciences confirmed the morality and ethics of that study (IR.REFERENCE.REC.1396.554).

\section{Consent for publication}

Not applicable.

\section{Availability of data and materials}

Upon request, we can offer onsite access to the data analyzed at Ahvaz Jundishapur University of Medical Sciences, Ahvaz, Iran.

\section{Competing interests}

Nothing to declare.

\section{Funding}

Vice-Chancellor's Office for Research funded support was this research.

\section{Authors' contributions}

The authors' responsibilities were as follows: MA were supervisor of the study. MA designed the study and questionnaire and also drafted the manuscript. $\mathrm{BCH}$ and $\mathrm{MD}$ conducted the study. A-BH helped study implementation. All authors contributed the design and data analysis and assisted in the preparation of the final version of the manuscript. All authors approved the final version of the manuscript.

\section{Acknowledgements}


This study was the result of a part of a Master's thesis fulfilled by Ms. Masoumeh Divdar at Ahvaz Jundishapur University of Medical Sciences with the code no. SDH-9614. We, hereby, appretiate the ViceChancellor's Office for Research for funding this project as well as authorities in community health centers in Izeh county and all pregnant women participating in this study.

\section{References}

1. Shahnazi H, Hosseintalaei M, Ghashghaei FE, Charkazi A, Yahyavi Y, Sharifirad G. Effect of Educational Intervention on Perceived Susceptibility Self-Efficacy and DMFT of Pregnant Women. Iranian Red Crescent Medical Journal. 2016;18(5).

2. Haerian Ardakani A, Morowatisharifabad M, Rezapour Y, Pourghayumi Ardakani A. Investigation of the Relationship of Oral Health Iteracy and Oral hygiene Self-Efficacy with Self-Reported Oral and Dental Health in Students. Toloo-e-behdasht. 2015;13(5):125-40.

3. Peyman N, Ezzati-Rastgar K, Tehrani H. The Impact of Educational Intervention Based on PEN-3 Model on Oral Health Behavior in Elementary School Students. Iranian Journal of Health Education and Health Promotion. 2016;4(2):149-57.

4. Tsuboya T, Aida J, Kawachi I, Katase K, Osaka K. Early life-course socioeconomic position, adult workrelated factors and oral health disparities: cross-sectional analysis of the J-SHINE study. BMJ open. 2014;4(10):e005701.

5. Masoe AV, Blinkhorn AS, Taylor J, Blinkhorn FA. Factors that influence the preventive care offered to adolescents accessing Public Oral Health services, nsW, Australia. Adolescent health, medicine and therapeutics. 2015;6:101.

6. Pakpour AH, Yekaninejad MS, Sniehotta FF, Updegraff JA, Dombrowski SU. The effectiveness of gainversus loss-framed health messages in improving oral health in Iranian secondary schools: a clusterrandomized controlled trial. Annals of Behavioral Medicine. 2014;47(3):376-87.

7. Marsh P. Contemporary perspective on plaque control. British dental journal. 2012;212(12):601.

8. Allameh M, Khademi H, Eslami M. A cross-sectional survey on relationship between some biologic maternal characteristics and dental status of pregnant women in Isfahan, Iran, in 2012. Journal of Oral Health and Oral Epidemiology. 2014;3(2):72-8.

9. Mills LW, Moses DT. Oral health during pregnancy. MCN: The American Journal of Maternal/Child Nursing. 2002;27(5):275-80.

10. Bird AL, Grant CC, Bandara DK, Mohal J, Atatoa-Carr PE, Wise MR, et al. Maternal health in pregnancy and associations with adverse birth outcomes: Evidence from Growing Up in New Zealand. Australian and New Zealand Journal of Obstetrics and Gynaecology. 2017;57(1):16-24.

11. George A, Dahlen HG, Reath J, Ajwani S, Bhole S, Korda A, et al. What do antenatal care providers understand and do about oral health care during pregnancy: a cross-sectional survey in New South Wales, Australia. BMC Pregnancy and Childbirth. 2016;16(1):382.

12. Silveira ML, Whitcomb BW, Pekow P, Carbone ET, Chasan-Taber L. Anxiety, depression, and oral health among US pregnant women: 2010 Behavioral Risk Factor Surveillance System. Journal of public health dentistry. 2015. 
13. Bayat F, Karimi-Shahanjarini A, Bashirian S, Faradmal J. Assessment of Dental Care and its Related Barriers in Pregnant Women of Hamadan City. Journal of Education and Community Health. 2016;3(1):20-7.

14. Maybodi FR, Haerian-Ardakani A, Vaziri F, Khabbazian A, Mohammadi-AsI S. CPITN changes during pregnancy and maternal demographic factors 'impact on periodontal health. Iranian journal of reproductive medicine. 2015;13(2):107.

15. Silk H, Douglass AB, Douglass JM, Silk L. Oral health during pregnancy. American family physician. 2008;77(8).

16. Hosein Kazemi H, Zeinal Zadeh M, Farsam F, Khafri S, Matloubi N. Pregnant women's self-report of oral health condition and its relation with oral clinical status. Iranian Journal of Obstetrics, Gynecology and Infertility. 2016;18(186):16-9.

17. Shamsi M, Hidarnia A, Niknami S, karimi M. Effects of Educational Programs on DMFT Plaque Index and Performance of Pregnant Women. J Mazand Univ Med Sci. 2013;23(100):62-72.

18. Tsakos G, Blair YI, Yusuf H, Wright W, Watt RG, Macpherson LM. Developing a new self-reported scale of oral health outcomes for 5-year-old children (SOHO-5). Health and quality of life outcomes. 2012;10(1):1.

19. Moawed S, Hawsawi A, AlAhmed SS, Al-Atawi N, Awadien AaZ. Knowledge and oral health care practices among Saudi pregnant women. Life Sci J. 2014;11(5):32-41.

20. Hoeft KS, Rios SM, Guzman EP, Barker JC. Using community participation to assess acceptability of "Contra Caries", a theory-based, promotora-led oral health education program for rural Latino parents: a mixed methods study. BMC oral health. 2015;15(1):1.

21. Karimy T, Saffari M , Sanaeinasab H, Khalagi K, M H-A.f Theory on Based Intervention Educational of Impact Patients of Change Lifestyle on Behavior Planned Infarction Myocardial with. Iranian Journal of Health Education \& Promotion 20163 (4):370- 80.

22. Quon AK. Exposure to gain-and loss-framed message picture books and its effect on preschoolers' acceptance of an unfamiliar or disliked vegetable: D'Youville College; 2014.

23. Bai L, Cai Z, Lv Y, Wu T, Sharma M, Shi Z, et al. Personal involvement moderates message framing effects on food safety education among medical university students in chongqing, china. International journal of environmental research and public health. 2018;15(9):2059.

24. Updegraff JA, Brick C, Emanuel AS, Mintzer RE, Sherman DK. Message framing for health: Moderation by perceived susceptibility and motivational orientation in a diverse sample of Americans. Health Psychology. 2015;34(1):20.

25. Ramezankhani A, Ghafari M, Naeimavi N , S. K, Ali montazeri. Effectiveness of Message Framing on Oral Health-related Behaviors. Payesh. 2016;6: 707-16.

26. Prokhorov AV, Machado TC, Calabro KS, Vanderwater EA, Vidrine DJ, Pasch KP, et al. Developing mobile phone text messages for tobacco risk communication among college students: a mixed methods study. BMC Public Health. 2017;17(1):137.

27. Akl EA, Oxman AD, Herrin J, Vist GE, Terrenato I, Sperati F, et al. Framing of health information messages. Cochrane Database of Systematic Reviews. 2011(12). 
28. DehdariT, Shojaei Zadeh D ZF, Rakhshani F. Communication and message design in health: tavangharan; 2013. $172 \mathrm{p}$.

29. Zahra M, Javad S, tahere E. The Effect of Framing Health Messages on Unreal Optimism, Practical Intention and Memory: The Role of Tactile / Contractive Behavioral Systems. 2017;17( 5 \# g00291):From page 563 to page 75 .

30. Merdasi F, Araban M, Saki MA. The Effect of Message-Framing on Breastfeeding Self-Efficacy Among Nulliparous Women in Shushtar, Iran. Electronic Physician. 2017;9(1):3554.

31. Z B, Zamani Alavijeh F , Nouhjah S, Shakerinejad Gh , Payami SP Comparing gain- and loss-framed message texting (SMS) on foot self-care behaviors among women with type 2 diabetes. Payesh. 2016;6:695.

32. Hajizadeh E, Asghari M. Methods and statistical analysis by looking at the research method in biotechnology and health sciences. 2011.

33. MICHAEL G. NEWMAN D, FACD. Newman and Carranza's Clinical Periodontology. 2015:86.

34. Gallagher KM, Updegraff JA. Health message framing effects on attitudes, intentions, and behavior: a meta-analytic review. Annals of behavioral medicine. 2012;43(1):101-16.

35. Rothman AJ, Bartels RD, Wlaschin J, Salovey P. The strategic use of gain-and loss-framed messages to promote healthy behavior: How theory can inform practice. Journal of communication. 2006;56(suppl_1):S202-S20.

36. Rothman AJ, Martino SC, Bedell BT, Detweiler JB, Salovey P. The systematic influence of gain-and lossframed messages on interest in and use of different types of health behavior. Personality and Social Psychology Bulletin. 1999;25(11):1355-69.

37. Ghajari H, Shakerinejad Gh, Hosseini SA, MH HZ. A study of the impact of message framing on calcium-rich foods intake in high school girls: a perspective of regulatory focus theory. Journal of the Iranian Institute for Health Sciences Research Payesh. 2016(2):163-71.

38. Pakpour Haji Agha A, Nourozi S, Yekaninejad MS, Mansouri A, S. C. Effect of message framing on improving oral health behaviors in students in Qazvin, Iran. Isfahan Dent. 2013; 8(6): 512-21.

39. Lai HS, Szeto GP, Chan CC. Injured workers' perception of loss and gain in the return to work process. Risk management and healthcare policy. 2017;10:7.

40. Uskul AK, Sherman DK, Fitzgibbon J. The cultural congruency effect: Culture, regulatory focus, and the effectiveness of gain-vs. loss-framed health messages. Journal of Experimental Social Psychology. 2009;45(3):535-41.

41. Sherman DK, Updegraff JA, Mann T. Improving oral health behavior: A social psychological approach. The Journal of the American Dental Association. 2008;139(10):1382-7.

42. Schneider TR, Salovey P, Apanovitch AM, Pizarro J, McCarthy D, Zullo J, et al. The effects of message framing and ethnic targeting on mammography use among low-income women. Health Psychology. 2001;20(4):256.

43. Gharaati F , Aghamolaei T, Hassani I, MohamadiR, MohsseniSh. The effect of educational intervention using mobile phone on self-care behaviors in patients with thalassemia major. Journal of Preventive 
Medicine. 2016;3(2):63-72.

44. Haghani F , Shahidi Sh, Manouchehri F, Kalantari B , Ghasemi G. The Effect of Distance Learning via SMS on Knowledge \& Satisfaction of Pregnant Women. Iranian Journal of Medical Education. 2016:4352.

45. Naderi F AM, Zare Bidaki M, Akbari Bourang M. The Effect of Mobile Learning on Metacognitive Selfregulation and Attitudes of Students of Allied Health Sciences. Iranian Journal of Medical Education. 2014;13(12):1001-10.

\section{Tables}

Table 1 - Comparison of mean and standard deviation of quantitative demographic variable

\begin{tabular}{|c|c|c|c|c|c|c|c|}
\hline Variable & $\begin{array}{c}\text { Gain-framed } \\
\text { Mean }\end{array}$ & Std. Deviation & $\begin{array}{c}\text { Loss-framed } \\
\text { Mean }\end{array}$ & Std. Deviation & $\begin{array}{c}\text { Control } \\
\text { Mean }\end{array}$ & Std. Deviation & $p$-value* \\
\hline Maternal age & 26.75 & 4.77 & 27.69 & 4.4 & 27.77 & 3.94 & 0.545 \\
\hline Ge & 22.97 & 3.71 & 22.38 & 3.36 & 24.33 & 3.93 & 0.076 \\
\hline
\end{tabular}

*Derived from t test

Table 2 - Comparison of frequency of qualitative demographic variables

\begin{tabular}{|c|c|c|c|c|c|}
\hline Variable & & (\%) Gain; n & (\%) Loss; $\mathrm{n}$ & (\%) Control; $\mathrm{n}$ & p-value* \\
\hline \multirow[t]{2}{*}{ Maternal occupation } & Employed & $(5.6) 2$ & (13.9) 5 & (5.6) 2 & 0.5 \\
\hline & Housewife & $34(94.4)$ & $31(86.1)$ & $34(94.4)$ & \\
\hline \multirow[t]{4}{*}{$\begin{array}{l}\text { Maternal } \\
\quad \text { level of education }\end{array}$} & Primary school & $3(8.3)$ & $2(5.6)$ & 0 & 0.463 \\
\hline & Middle school & $5(13.9)$ & $3(8.3)$ & $6(16.7)$ & \\
\hline & High school & $16(44.4)$ & $15(41.7)$ & $12(33.3)$ & \\
\hline & University degree & $12(33.3)$ & $16(44.4)$ & $18(50)$ & \\
\hline \multirow[t]{2}{*}{ Previous pregnancy history } & Yes & $11(30.6)$ & $14(38.9)$ & $20(55.6)$ & 0.091 \\
\hline & No & $25(69.4)$ & $22(61.1)$ & $16(44.4)$ & \\
\hline \multirow[t]{3}{*}{ Ethnicity } & Lur & $33(91.7)$ & $34(94.4)$ & $35(97.2)$ & 0.692 \\
\hline & Arab & $2(5.6)$ & 0 & 0 & \\
\hline & Persian & $1(2.8)$ & $2(5.6)$ & $1(2.8)$ & \\
\hline \multirow[t]{3}{*}{ Household income } & Poor & $3(8.3)$ & $9(25)$ & $5(13.9)$ & 0.369 \\
\hline & Moderate & $14(38.9)$ & $10(17.8)$ & $14(38.9)$ & \\
\hline & Good & $19(52.8)$ & $17(47.2)$ & $17(47.2)$ & \\
\hline \multirow[t]{2}{*}{ Place of residence } & Urban & $32(88.9)$ & $35(97.2)$ & $35(97.2)$ & 0.362 \\
\hline & Rural & $4(11.1)$ & $1(2.8)$ & $1(2.8)$ & \\
\hline \multirow[t]{2}{*}{ Coverage of healthcare insuran } & Yes & $31(86.1)$ & $29(80.6)$ & $29(80.6)$ & 0.775 \\
\hline & No & $5(13.9)$ & $7(19.4)$ & $7(19.4)$ & \\
\hline
\end{tabular}

*Derived from chi- square 
Table 3 - Comparison of constructs and dental plaque in three groups at baseline and follow-up

\begin{tabular}{|c|c|c|c|c|c|c|c|}
\hline \multirow{4}{*}{ Variables } & & & & Groups & & & \multirow{3}{*}{ p-value* } \\
\hline & & & & & & & \\
\hline & $\begin{array}{l}\text { Gain- } \\
\text { framed Mean } \pm \text { Sd }\end{array}$ & $\begin{array}{l}\text { Gain-framed } \\
\text { Mean } \pm \text { Sd }\end{array}$ & $\begin{array}{l}\text { Loss- } \\
\text { framed Mean } \pm \text { Sd }\end{array}$ & $\begin{array}{l}\text { Loss-framed } \\
\text { Mean } \pm \text { Sd }\end{array}$ & $\begin{array}{c}\text { Control Mean } \pm \\
\text { Sd }\end{array}$ & $\begin{array}{l}\text { Control } \\
\text { Mean } \pm \text { Sd }\end{array}$ & \\
\hline & $\begin{array}{c}\text { before } \\
\text { intervention }\end{array}$ & $\begin{array}{c}\text { after } \\
\text { intervention }\end{array}$ & $\begin{array}{l}\text { before } \\
\text { intervention }\end{array}$ & $\begin{array}{c}\text { after } \\
\text { intervention }\end{array}$ & $\begin{array}{c}\text { before } \\
\text { intervention }\end{array}$ & $\begin{array}{c}\text { after } \\
\text { intervention }\end{array}$ & \\
\hline Knowledge & $5.69 \pm 11.65$ & $11.97 \pm 1.33$ & $6.22 \pm 1.57$ & $11.94 \pm 1.10$ & $5.70 \pm 1.71$ & $6.08 \pm 1.79$ & $\mathrm{p}<0.001$ \\
\hline Attitude & $39.42 \pm 4.71$ & $44.42 \pm 3.26$ & $39.85 \pm 4.92$ & $44.40 \pm 3.62$ & $5.55 \pm 37.94$ & $38.82 \pm 4.21$ & $\mathrm{p}<0.001$ \\
\hline $\begin{array}{l}\text { Behavioral } \\
\text { intention }\end{array}$ & $24.37 \pm 2.61$ & $27.28 \pm 2.05$ & $24.51 \pm 2.74$ & $26.77 \pm 2.34$ & $24.05 \pm 2.94$ & $23.67 \pm 2.71$ & $\mathrm{p}<0.001$ \\
\hline Self-efficacy & $34.48 \pm 3.84$ & $38.91 \pm 3.23$ & $34.37 \pm 4.20$ & $38.34 \pm 3.42$ & $34.29 \pm 5.24$ & $33.79 \pm 5.15$ & $\mathrm{p}<0.001$ \\
\hline Practice & $6.02 \pm 2.56$ & $11 \pm 1.98$ & $5.51 \pm 2.06$ & $10.25 \pm 1.48$ & $5.94 \pm 2.24$ & $7.55 \pm 2.21$ & $\mathrm{p}<0.001$ \\
\hline $\begin{array}{l}\text { Dental } \\
\text { plaque }\end{array}$ & $36.18 \pm 14.99$ & $19.71 \pm 9.71$ & $38.69 \pm 15.15$ & $23.67 \pm 10.72$ & $39.03 \pm 12.96$ & $36.87 \pm 11.74$ & $\mathrm{p}<0.001$ \\
\hline
\end{tabular}

*Derived from ANOVA

Figures 


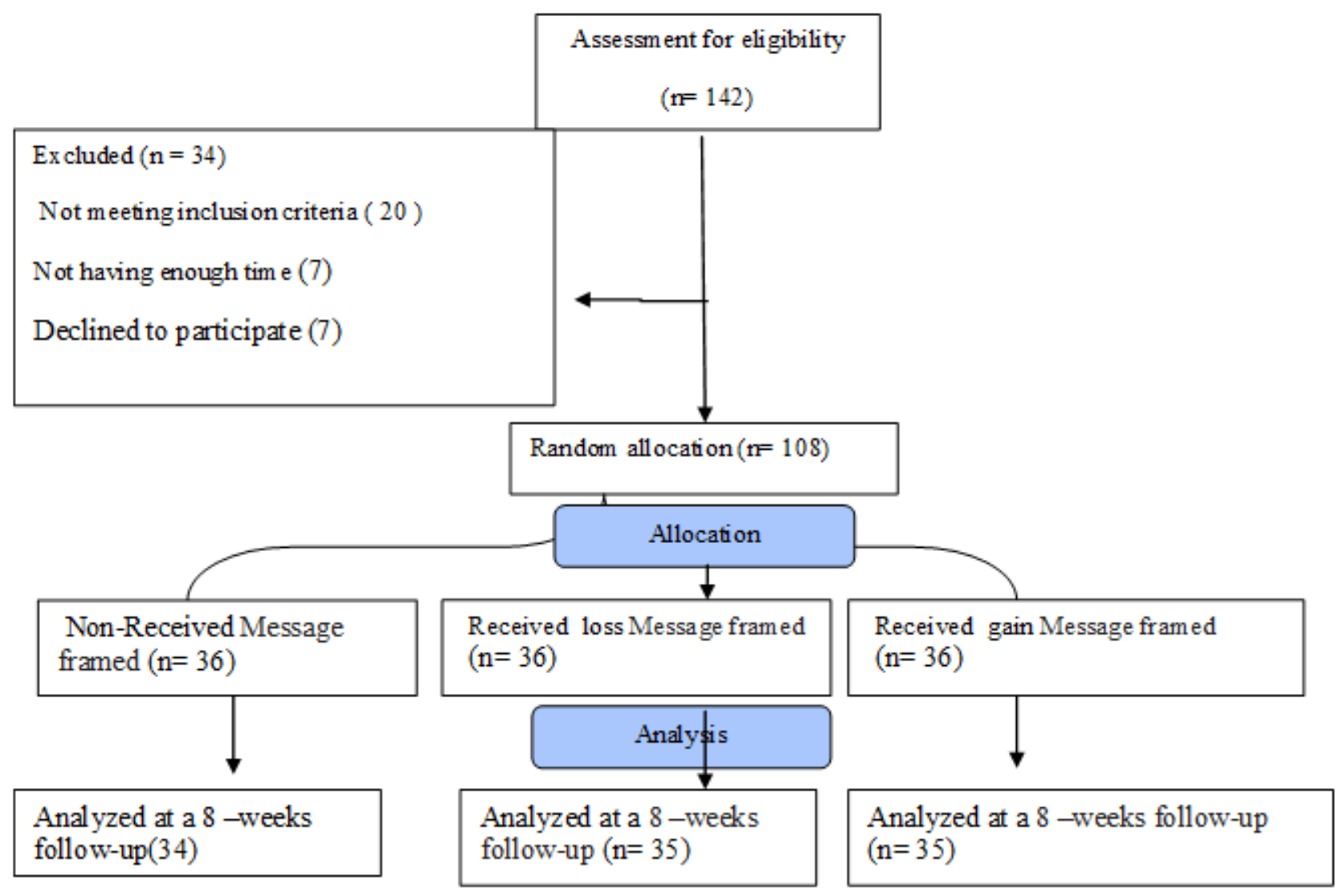

\section{Figure 1}

Flow diagram of the participants

\section{Supplementary Files}

This is a list of supplementary files associated with this preprint. Click to download.

- Questionnire.Divdaroc.doc

- CONSORT2010ChecklistDIVDAR.doc 